\title{
Cell proliferation in three types of Barrett's epithelium ${ }^{1}$
}

\author{
L J PELLISH, J A HERMOS, AND G L EASTWOOD 2
}

From the Departments of Medicine, West Roxbury and Boston Veterans Administration Hospitals, Peter Bent Brigham Hospital, Harvard Medical School, and Boston University School of Medicine, Boston, USA

SUMMARY Barrett's epithelium is a columnar, possibly premalignant, metaplasia of the oesophagus. To study the pattern of epithelial renewal in this disorder, we localised the lower oesophageal sphincter by manometry in 12 patients with known Barrett's epithelium, obtained multiple suction biopsies above the sphincter, and organ cultured the biopsies over $3 \mathrm{H}$-TdR-containing medium to label proliferating cells. Of 23 biopsies from the 12 patients, 13 were specialised columnar type, three were junctional type, and seven were fundic type. None of the patients showed clinical evidence of oesophageal carcinoma, and oesophageal cytological examinations were uniformly negative for neoplastic cells. When compared with control gastric fundic biopsies from normal volunteers, mean values for the labelling index and the proportion of the pit which was occupied by the proliferative zone in Barrett's biopsies were not significantly different. However, four individual Barrett's biopsies (three specialised columnar type and one junctional type) did have a proliferative zone which occupied a greater proportion of the pit than did the widest control zone. We propose that the pattern of epithelial proliferation in Barrett's epithelium in general is similar to that found in other gastrointestinal columnar epithelia. However, a minority of patients with Barrett's epithelium may have an expanded proliferative zone. The clinical implications of an expanded proliferative zone with regard to the subsequent development of oesophageal carcinoma require further investigation.

The columnar cell lined oesophagus, commonly called Barrett's epithelium, is a metaplasia of the distal oesophagus which is associated with chronic reflux oesophagitis. Several retrospective studies and case reports have indicated that there is an increased frequency of oesophageal adenocarcinoma in patients with Barrett's epithelium (Carrie, 1950; Hawe et al., 1973; Hankins et al., 1974; Belladonna et al., 1974; Naef et al., 1975; McDonald et al., 1977; Haggitt et al., 1978). The largest study described 12 cases of adenocarcinoma among 140 patients who had columnar lined oesophagus (Naef et al., 1975). More recently, a retrospective review of 14 cases of primary oesophageal adenocarcinoma disclosed that 12 of them arose in Barrett's epithelium (Haggitt et al., 1978). Abnormal patterns of epithelial renewal have been associated with frank neoplasia or

This study was supported by Veterans Administration funds, MRIS No. 690-2037.

${ }^{2}$ Address for communications: Gregory L Eastwood, MD, Gastroenterology Divisions, University of Massachusetts Medical School, 55 Lake Avenue North, Worcester, Massachusetts 01605, USA.

Received for publication 26 July 1979 preneoplastic lesions elsewhere in the gastrointestinal tract (Cole and McKalen, 1963; Deschner et al., 1966; Lieb and Lisco, 1966; Winawer and Lipkin, 1969; Bleiberg et al., 1970; Bleiberg et al., 1972; Eastwood and Trier, 1973). Thus, we performed the following study to define the characteristics of epithelial proliferation in Barrett's epithelium and to determine whether differences in proliferation exist between the three types of Barrett's epithelium as recently described by Paull et al. (1976).

\section{Methods}

\section{PATIENTS}

Twelve patients with biopsy-proven Barrett's oesophagus entered the study. (The study was approved by the West Roxbury VA Hospital and the Boston VA Hospital Human Studies Committees, and each patient gave informed, written consent to participate in the study.) Ten patients underwent wash oesophageal cytology with fluoroscopic control one to seven days before biopsy. The other two patients had had recent oesophagoscopy with brush cytology. 
Eleven of the 12 Patients had manometrically guided suction biopsies. A single lumen manometry tube was taped to a multipurpose suction biopsy tube (Brandborg et al., 1969) so that the port of the biopsy tube extended $1 \mathrm{~cm}$ beyond the end of the manometry tube. The first biopsy was taken at least $2 \mathrm{~cm}$ above the manometrically defined lower oesophageal sphincter, with subsequent biopsies taken at 1 to $2 \mathrm{~cm}$ intervals cephalad. The twelfth patient underwent suction biopsy immediately after oesophagoscopy had defined the levels of the squamocolumnar junction and the gastroesophageal junction. We obtained a total of 23 biopsies which were suitable for study from the 12 patients who had Barrett's epithelium.

Oriented biopsies were organ cultured by established methods for three hours over a titrated thymidine containing medium $(10 \mu \mathrm{Ci} / \mathrm{ml}$, specific gravity $6.7 \mathrm{Ci} / \mathrm{mM}$, New England Nuclear Corporation, Boston, Massachusetts) (Browning and Trier, 1969; Eastwood and Trier, 1973). Five micron sections were cut from paraffin embedded tissue. Slides were dipped in Kodak NTB3 photographic emulsion, diluted $1: 1$ with distilled water, and exposed in light-proof boxes at $2^{\circ} \mathrm{C}$ for six weeks. The slides were then developed in Kodak D 19, fixed, and stained with haematoxylin and eosin.

Ten control biopsies of fundic mucosa were obtained from six normal volunteers, organ cultured, and processed for autoradiography (with the help of Dr Ramzi Assad) as described above. The autoradiographic slides of control and Barrett's epithelium were randomised and viewed under the light microscope without knowledge of their origin. The histological type of Barrett's epithelium, as defined by Paull et al. (1976), was identified for each biopsy. The three types of oesophageal columnar epithelium are the specialised columnar type, which is characterised by intestinal type goblet cells and mucous glands; the junctional type, which has gastric type pits and cardiac mucous glands devoid of parietal cells; and the gastric fundic type, which also has gastric type pits but glands which do contain parietal cells and chief cells. Each biopsy was also evaluated for the degree of inflammatory infiltration, which was graded arbitrarily on a scale of 0 to $4+$, and for the presence of dysplasia.

To measure epithelial proliferation, five welloriented pits which contained labelled cells were selected from each biopsy. Labelled cells were identified by an accumulation of black silver granules overlying the nucleus which exceeded the background labelling by at least four-fold. First, we counted the total number of cells in each pit. Secondly, we counted the number of cells in the proliferative zone, which is the region of active
DNA synthesis and cell division; the proliferative zone was defined as the total number of cells below the highest labelled cells on either side of the pit. Thirdly, we counted the number of labelled cells within the proliferative zone. Data were compared for statistical significance between two given groups by use of the $t$ test for independent means.

\section{Results}

The 23 biopsies from the 12 patients who had Barrett's epithelium included 13 which were specialised columnar type, three which were junctional type, and seven which were fundic type. Of course, all 10 biopsies from the six normal volunteers contained gastric fundic mucosa.

The degree of inflammation in the biopsies varied among the histological groups. On a scale of 0 to

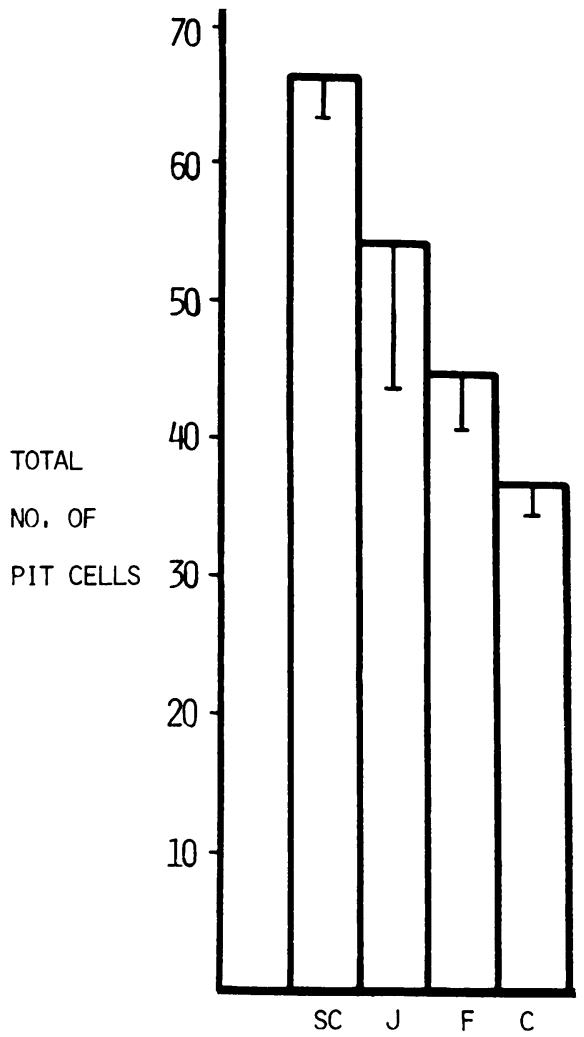

Fig. 1 Total number of cells per pit. Key to this and subsequent figures: $S C$ : specialised columnar type Barrett's epithelium. J: junctional type Barrett's epithelium. F: fundic type Barrett's epithelium. C: control gastric fundic epithelium. 1 : standard error of the mean. Significant differences: $S C$ versus $C(\mathrm{P}<0.005)$, $J$ versus $C(\mathrm{P}<0.05), F$ versus $C(\mathrm{P}<0.05), S C$ versus $F(\mathrm{P}<0.0005)$. 


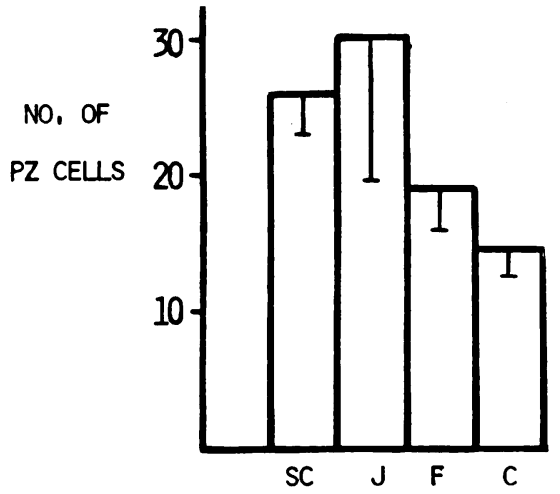

Fig. 2 Number of cells in the proliferative zone (PZ). Significant differences: $S C$ versus $C(\mathrm{P}<0.005), J$ versus $C(\mathrm{P}<0.05)$.

$4+$, the mean of the specialised columnar type biopsies was $1 \cdot 7$, the mean of the junctional type biopsies was $3 \cdot 0$, and the mean of the fundic type biopsies was $2 \cdot 4$. The mean of the fundic control biopsies was $\mathbf{0 \cdot 3}$, which included two biopsies, from separate individuals, which had $1+$ and $2+$ inflammation.

All cytologies and biopsies were negative for severe atypia, dysplasia, or neoplasm.

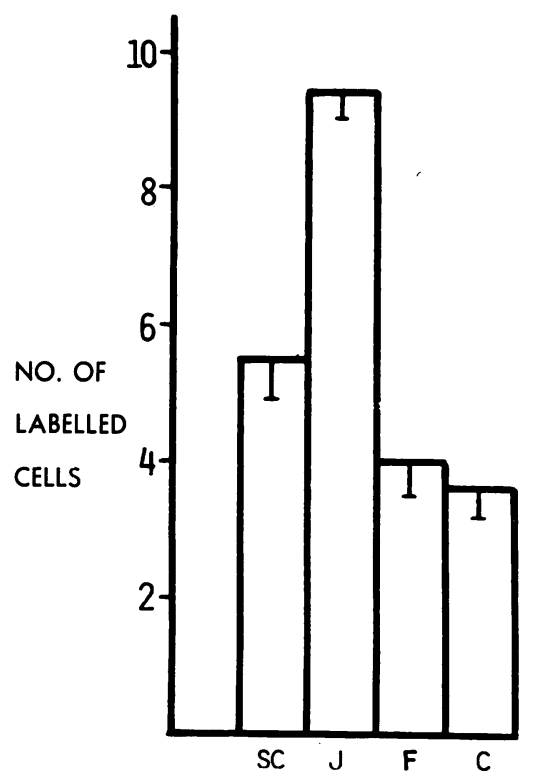

Fig. 3 Number of labelled cells within the proliferative zone. Significant differences: $S C$ versus $C(\mathrm{P}<0.01)$, $J$ versus $C(\mathrm{P}<0.01), J$ versus $S C(\mathrm{P}<0.05), J$ versus $F$ $(\mathrm{P}<0.05)$.
Table Proportion of pit occupied by proliferative zone (number of proliferative zone cells/total number of cells in pit)

\begin{tabular}{|c|c|c|c|}
\hline \multirow{2}{*}{$\begin{array}{l}\text { Control gastric } \\
\text { fundic biopsies } \\
(n=10)\end{array}$} & \multicolumn{3}{|l|}{ Barrett's biopsies } \\
\hline & $\begin{array}{l}\text { Specialised columnar } \\
(n=13)\end{array}$ & $\begin{array}{l}\text { Junctional } \\
(n=3)\end{array}$ & $\begin{array}{l}\text { Fundic } \\
(n=7)\end{array}$ \\
\hline $\begin{array}{l}.22 \\
.26 \\
.26 \\
.32 \\
.38 \\
.43 \\
.43 \\
.44 \\
.47 \\
.61\end{array}$ & $\begin{array}{l}.21 \\
.26 \\
.27 \\
.28 \\
.30 \\
.32 \\
.33 \\
.35 \\
.36 \\
.48 \\
.63^{*} \\
.67^{*} \\
.76^{*}\end{array}$ & $\begin{array}{l}.34 \\
.50 \\
.74^{*}\end{array}$ & $\begin{array}{l}.20 \\
.29 \\
.36 \\
.49 \\
.53 \\
.55 \\
.57\end{array}$ \\
\hline
\end{tabular}

*Value exceeds the highest value for the control biopsies.

PROLIFERATION MEASUREMENTS

The total number of cells per pit was significantly greater in specialised columnar, junctional, and fundic type Barrett's biopsies versus control gastric biopsies, and in specialised columnar type biopsies versus fundic type biopsies (Fig. 1). The number of cells in the proliferative zone was significantly greater in both specialised columnar and junctional type biopsies versus control biopsies (Fig. 2). The number of labelled cells within the proliferative zone was significantly gieater in specialised columnar and junctional biopsies versus control biopsies, and in junctional biopsies versus specialised columnar and fundic biopsies (Fig. 3).

The fraction of cells in the proliferative zone which were labelled (number of labelled cells/number of proliferative zone cells=labelling index) was significantly greater only in the junctional type

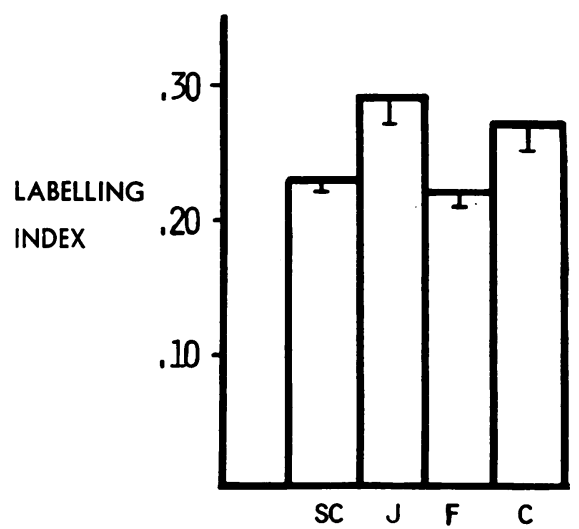

Fig. 4 Labelling index (number of cells/number of proliferative zone cells). Significant difference: $J$ versus $F$ $(\mathrm{P}<0.05)$. 


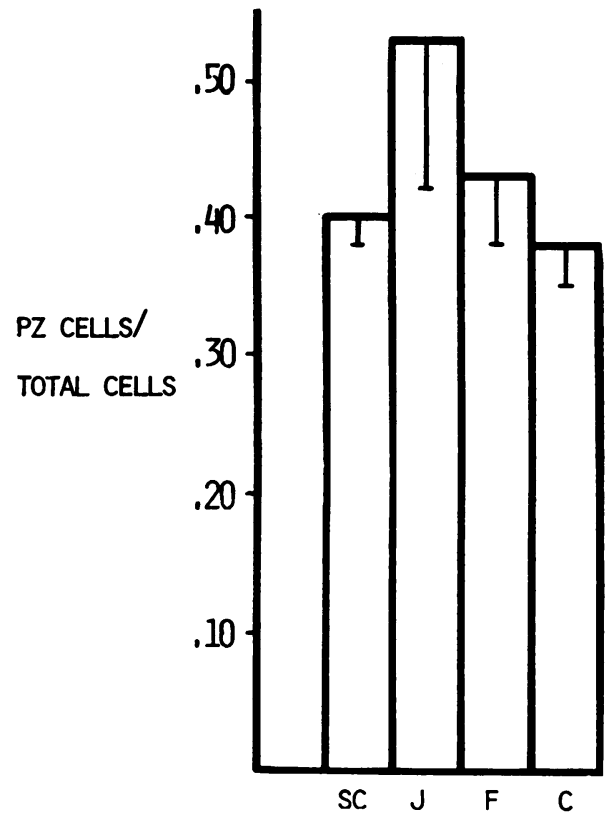

Fig. 5 Number of proliferative zone cells/total number of cells in the pit (proportion of the pit which is occupied by the proliferative zone). Significant differences: none.

versus fundic type biopsies (Fig. 4), whereas the proportion of the pit which was occupied by the proliferative zone (number of proliferative zone cells/total cells in the pit) was not significantly different between any of the groups (Fig. 5). Because individual Barrett's biopsies which may have an expanded proliferative zone when compared with normal control biopsies could be obscured by the mean values, we compared the proportion of the pit which was occupied by the proliferative zone for each biopsy within each study group (Table). Three specialised columnar type biopsies and one junctional type biopsy had proliferative zones which occupied a greater proportion of the pit than did the widest proliferative zone in the control gastric fundic biopsies.

\section{Discussion}

This study shows that, with respect to the absolute measurements of epithelial proliferation-namely, (1) the total number of cells in each pit, (2) the number of cells in the proliferative zone, and (3) the number of labelled cells within the proliferative zone -the values in all three types of Barrett's epithelium were greater than in control gastric fundic mucosa. However, the difference between fundic type Barrett's epithelium and control tissue with respect to the number of cells in the proliferative zone and the number of labelled cells did not reach statistical significance.

On the other hand, there was no statistical difference between any of the groups with respect to the relative measurements of epithelial proliferation -that is, the labelling index and the proportion of the pit which was occupied by the proliferative zone-except for a statistically greater labelling index in Barrett's junctional type versus Barrett's fundic type biopsies. Although the mean values were little different, four individual Barrett's biopsies (three specialised columnar type and one junctional type) did have a proliferative zone which occupied a greater proportion of the pit than did the widest control zone. Whether these biopsies are from patients who, indeed, have abnormal proliferation kinetics which subsequently will predispose them to develop neoplasia is conjectural. None of the patients in our series had clinical, histological, or cytological evidence for neoplasia, and the four biopsies in question were not distinguished by having any more or less inflammation than other Barrett's biopsies.

The degree of inflammation in all three types of Barrett's epithelium exceeded the control biopsies, appearing greatest in the Barrett's junctional biopsies. Junctional biopsies also had the highest measurements of epithelial proliferation, both absolute and relative, a fact which suggests that the differences which we observed may not have been due to any intrinsic difference in epithelial kinetics between the types of epithelium, but were in response to inflammation. The relationship between inflammatory conditions and enhanced epithelial proliferation has been documented for other gastrointestinal tissues (Bleiberg et al., 1970; Trier and Browning, 1970; Eastwood and Trier, 1973).

A recent paper by Herbst et al. (1978) is relevant to our observations. They studied cell proliferation in oesophageal biopsies from 11 patients who had Barrett's epithelium, using an in vitro double labelling technique which is not strictly comparable with our organ culture method. Nevertheless, they found a mean labelling index of $23.3 \%$, which is remarkably similar to the mean labelling indices in the three types of Barrett's epithelium in our study-namely, $23 \%$ in the specialised columnar type, $29 \%$ in the junctional type, and $22 \%$ in the fundic type. Two of the 11 patients studied by Herbst et al. had adenocarcinoma of the oesophagus, but the carcinoma was not present in the biopsies studied. In those two patients, as well as in one of the nine patients without adenocarcinoma, labelling of surface columnar cells was identified. No control biopsies of gastric mucosa were included in that study, so we do not 
know whether some surface labelling might be expected in a portion of biopsies subjected to the labelling methods which Herbst et al. used. In our study, we found that one of the 13 specialised columnar type biopsies, two of the three junctional type biopsies, and three of the seven fundic type biopsies contained at least one labelled surface cell. However, three of the 10 fundic control biopsies also had surface labelling, which suggests that, with our methods, labelling of isolated surface cells may not indicate abnormal epithelial renewal, but rather may be an artefact of tissue handling.

Abnormal epithelial renewal-that is, expansion of the proliferative zone beyond its normal limitshas been associated with frank neoplasia or preneoplastic lesions in a number of gastrointestinal epithelia. These include normal appearing colonic mucosa adjacent to polyps (Cole and McKalen, 1963; Deschner et al., 1966; Bleiberg et al., 1972), hyperplastic mucosa adjacent to rectal carcinoma (Lieb and Lisco, 1966), the colonic mucosa of patients with ulcerative colitis (Bleiberg et al., 1970; Eastwood and Trier, 1973), and atrophic intestinalised gastric mucosa adjacent to gastric carcinoma (Winawer and Lipkin, 1969). Current evidence strongly implicates Barrett's epithelium as a premalignant condition (Carrie, 1950; Hawe et al., 1973; Hawkins et al., 1974; Belladonna et al., 1974; Naef et al., 1975; McDonald et al., 1977; Haggitt et al., 1978), yet, in our study, we were unable to identify an expanded proliferative zone as being characteristic of Barrett's epithelium. Nevertheless, four Barrett's biopsies did have a proliferative zone which was expanded beyond the widest zone among the control biopsies of the gastric fundus.

Our findings are consistent with the supposition that all three types of Barrett's epithelium, when not associated with evidence for neoplasia, in general have proliferation kinetics which are typical of normal epithelia elsewhere in the gastrointestinal tract. The absolute measurements of epithelial proliferation in Barrett's biopsies may be greater than in control biopsies simply because Barrett's epithelium is a different type of epithelium, which is directly comparable with no other epithelium. However, a minority of patients who have Barrett's epithelium may have altered proliferation kinetics, such as expansion of the proliferative zone. Whether identification of an expanded proliferative zone will predict those individuals who are more likely to develop cancer is a subject which requires further investigation.

The authors thank Emily Fant and Forrest Quimby for their technical assistance in these studies.

\section{References}

Belladonna, J. A., Hajdu, S. I., Bains, M. S., and Winawer, S. J. (1974). Adenocarcinoma in situ of Barrett's esophagus diagnosed by endoscopic cytology. New England Journal of Medicine, 291, 895-896.

Bleiberg, H., Mainguet, P., and Galand, P. (1972). Cell renewal in familial polyposis: comparison between polyps and adjacent healthy mucosa. Gastroenterology, 63, 240-245.

Bleiberg, H., Mainguet, P., Galand, P., Chretien, J., and Dupont-Mairesse, N. (1970). Cell renewal in the human rectum. In vitro autoradiographic study on active ulcerative colitis. Gastroenterology, 58, 851-855.

Brandborg, L. L., Rubin, G. E., and Quinton, W. E. (1959). A multi-purpose instrument for suction biopsy of the esophagus, stomach, small bowel and colon. Gastroenterology, 37, 1-16.

Browning, T. H., and Trier, J. S. (1969). Organ culture of mucosal biopsies of human small intestine. Journal of Clinical Investigation, 48, 1423-1432.

Carrie, A. (1950). Adenocarcinoma of the upper end of the oesophagus arising from ectopic gastric epithelium. British Journal of Surgery, 37, 474.

Cole, J. W., and McKalen, A. (1963). Studies on the morphogenesis of adenomatous polyps in the human colon. Cancer, 16, 998-1002.

Deschner, E. E., Lipkin, M., and Solomon, C. (1966). Study of human rectal epithelial cells in vitro. II. $\mathbf{H}^{3}$ thymidine incorporation into polyps and adjacent mucosa. Journal of the National Cancer Institute, 36, 849-855.

Eastwood, G. L., and Trier, J. S. (1973). Organ culture of human rectal mucosa. Gastroenterology, 64, 375-382.

Eastwood, G. L., and Trier, J. S. (1973). Epithelial cell renewal in cultured rectal biopsies in ulcerative colitis. Gastroenterology, 64, 383-390.

Haggitt, R. C., Tryzelaar, J., Ellis, F. H., and Colcher, H. (1978). Adenocarcinoma complicating columnar epithelium-lined (Barrett's) esophagus. American American Journal of Clinical Pathology, 70, 1-5.

Hankins, J. R., Cole, F. N., Attar, S., Frost, J. L., and McLaughlin, J. S. (1974). Adenocarcinoma involving the esophagus. Journal of Thoracic and Cardiovascular Surgery, 68, 148-158.

Hawe, A., Payne, W. S., Weiland, L. H., and Fontana, R. S. (1973). Adenocarcinoma in the columnar epithelial lined lower (Barrett) oesophagus. Thorax, 28, 511-514.

Herbst, J. J., Berenson, M. M., McCloskey, D. W., and Wiser, W. C. (1978). Cell proliferation in esophageal columnar epithelium (Barrett's esophagus). Gastroenterology, 75, 683-687.

Lieb, L. M., and Lisco, H. (1966). In vitro uptake of titrated thymidine by carcinoma of the human colon. Cancer Research, 26, 733-740.

McDonald, G. B., Brand, D. L., and Thorning, D. R. (1977). Multiple adenomatous neoplasms arising in columnar-lined (Barrett's) esophagus. Gastroenterology, 72, 1317-1321.

Naef, A. P., Savary, M., and Ozzello, L. (1975). Columnar- 
lined lower esophagus: an acquired lesion with malignant predispcsition. Journal of Thoracic and Cardiovascular Surgery, 70, 826-835.

Paull, A., Trier, J. S., Dalton, M. D., Camp, R. C., Loeb, P., and Goyal, R. K. (1976). The histologic spectrum of Barrett's esophagus. New England Journal of Medicine, 295, 476-480.
Trier, J. S., and Browning, T. H. (1970). Epithelial-cell renewal in cultured duodenal biopsies in celiac sprue. New England Journal of Medicine, 283, 1245-1250.

Winawer, S., and Lipkin, M. (1969). Cell proliferation kinetics in the gastrointestinal tract of man. IV. Cell renewal in the intestinalized gastric mucosa. Journal of the National Cancer Institute, 42, 9-17. 